\title{
In-situ sputter deposition of PT and PZT films on Platinum and $\mathrm{RuO}_{2}$ electrodes
}

\author{
T. Maeder, P. Muralt, L. Sagalowicz and N. Setter \\ Laboratoire de Céramique, Ecole Polytechnique Fédérale de Lausanne, CH-1015 Lausanne, Switzerland \\ Original version: Microelectronic Engineering 29 (1-4), 177-180, 1995. \\ http://hdl.handle.net/10.1016/0167-9317(95)00139-5
}

\begin{abstract}
The in-situ growth of $\mathrm{PbZr}_{x} \mathrm{Ti}_{1-x} \mathrm{O}_{3}(\mathrm{PZT})$ and $\mathrm{PbTiO}_{3}(\mathrm{PT})$ thin films by reactive sputter deposition has been investigated for applications with silicon substrates. In-situ deposition from three simultaneously operating magnetron sources was applied. At the selected growth temperature range $\left(550-600{ }^{\circ} \mathrm{C}\right)$, selfstabilisation of lead composition by a large desorption rate of $\mathrm{Pb}$ on stoichiometric PZT surfaces has been observed. Interlayer mixing was found to be limited to a few monolayers. Both $\mathrm{Pt}$ and $\mathrm{RuO}_{2}$ on $\mathrm{Si}-\mathrm{SiO}_{2}$ wafers were used as top and bottom electrodes. The type of bottom electrode, together with the lead flux and the presence of a bottom PT layer to help nucleate the growth of PZT, was found to have a marked influence on the crystallisation behaviour of the PZT films. Dielectric characterisation has been performed on the films, and the dependence on the deposition parameters is discussed.
\end{abstract}

\section{Introduction}

Recently, films of ferroelectric ceramics such as PZT and PT have received considerable attention. Their dielectric, piezoelectric (PZT) and pyroelectric (PT) properties can be applied to the fabrication of integrated devices such as memories [1], micromechanical devices [2, 3], and infrared detector arrays. For memories, $\mathrm{RuO}_{2}$ has emerged as an alternative bottom electrode to $\mathrm{Pt}$, leading to better fatigue properties [4].

PZT films may be grown by various methods [5-7]. In this work, the films were grown by an in-situ (without post-anneal) reactive sputtering technique [8] on $\mathrm{Si}_{-} \mathrm{SiO}_{2}$ wafers metallised with $\mathrm{Pt}$ and $\mathrm{RuO}_{2}$ electrodes.

Crystallisation of PZT is expected to depend on the bottom electrode. On Pt, it had been found $[4,9]$ that a thin $(30 \mathrm{~nm})$ seed PT layer could nucleate growth of PZT along $<100>$. For $\mathrm{RuO}_{2}$ [10], a second phase, identified as lead ruthenate $\left(\mathrm{Pb}_{2} \mathrm{Ru}_{2} \mathrm{O}_{7}\right)$, was seen at the $\mathrm{RuO}_{2}-\mathrm{PZT}$ interface. Also, $\mathrm{RuO}_{2}$ might not be stable at the low oxygen pressure (about $2 \mathrm{~Pa}$ ), high temperature and plasma bombardment during PZT deposition.

\section{Experimental}

\subsection{Bottom electrodes}

4" Si wafers, covered with $1 \mu \mathrm{m}$ of thermal oxide $\left(\mathrm{SiO}_{2}\right)$, were used as substrates. They were covered with a $\mathrm{TiO}_{2}$ (adhesion layer) - $\mathrm{Pt}$ sequence [11] or $\mathrm{TiO}_{2}-\mathrm{RuO}_{2}$ by sputtering at $550-600^{\circ} \mathrm{C}$ in a Nordiko 2000 chamber. Other information is given in table 1.

\subsection{PT and PZT deposition}

The PT and PZT films were deposited in an in-situ multimagnetron reactive sputtering process (in the same Nordiko 2000) [8]. Typical parameters are given in [9, 12]. For PZT, in order to enhance crystallisation and orientation, a $30 \mathrm{~nm}$ thick seed Ti-rich layer was deposited prior to the main PZT deposition $[4,9]$. 
Table 1. Metallisations

\begin{tabular}{|l|c|c|}
\hline Type & Pt & $\mathbf{R u O}_{\mathbf{2}}$ \\
\hline Thickness [nm] & 100 & 350 \\
\hline Morphology & columnar & columnar \\
\hline Orientation & $<111>$ & random \\
\hline
\end{tabular}

\subsection{Film Characterisation}

Films were characterised by X-ray diffraction (XRD), Scanning and transmission electron microscopy (SEM and TEM). Electrical property measurements were carried out on $0.6 \mathrm{~mm}$ diameter sputtered $\mathrm{Pt}$ or $\mathrm{RuO}_{2}$ top electrodes, according to the bottom metallisation. Dielectric constant and loss were measured using an impedance analyser (HP 4192A) at $100 \mathrm{mV}$.

\section{Results}

\subsection{Effect of lead flux on film crystallisation}

Because of large desorption of lead oxide at high temperature and under plasma bombardment, a considerable excess lead flux must be supplied. Figures 1 and 2 show the lead content in the deposited films as a function of lead flux, for PT [12] and PZT with a thin PT seed layer on Pt. Deposition rate corresponded to about one monolayer per turn. The X-ray diffraction (XRD) characteristics are also given for both substrates. Lead contents were essentially identical on Pt and $\mathrm{RuO}_{2}$.

The lead composition is estimated from film thickness measurements, assuming all $\mathrm{TiO}_{2}$ and $\mathrm{ZrO}_{2}$ remain on film [9].

$$
\frac{\mathrm{Pb}}{\mathrm{Zr}+\mathrm{Ti}} \cong \frac{\mathrm{R}-\mathrm{R}_{\mathrm{ZT}}}{\mathrm{R}_{\mathrm{PZT}}-\mathrm{R}_{\mathrm{ZT}}}
$$

$\mathrm{Pb} /(\mathrm{Zr}+\mathrm{Ti})$ is film lead content, $\mathrm{R}$ is measured rate, $\mathrm{R}_{\mathrm{ZT}}$ is measured $\mathrm{ZrO}_{2} / \mathrm{TiO}_{2}$ rate obtained by running without lead, and $\mathrm{R}_{\mathrm{PZT}}$ is the expected stoichiometric PZT rate estimated from $\mathrm{R}_{\mathrm{ZT}}$.

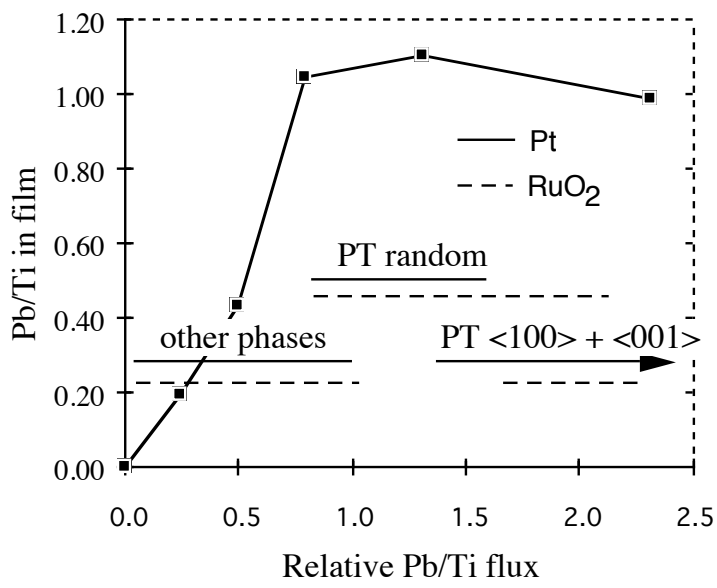

Figure 1. Estimated lead content in PT

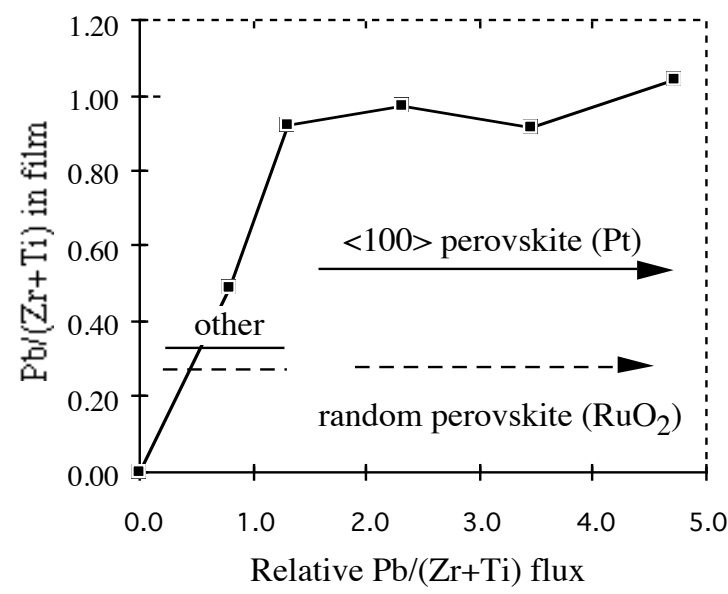

Figure 2. Estimated lead content in PZT 
The lead content saturates both for PT and PZT at high lead fluxes. On Pt, the thin PT seed layer allows crystallisation of $\langle 100>K 001>$ orientation, even at low lead fluxes. However, $30 \mathrm{~nm}$ is apparently not enough to establish oriented growth on the random $\mathrm{RuO}_{2}$, and random orientation results. The deposition process clearly favours $<100>/<001>$ growth for PT, since this orientation becomes dominant also on $\mathrm{RuO}_{2}$ when $300 \mathrm{~nm}$ are deposited. On the other hand, the PZT deposition seems more "orientation neutral", and follows the orientation of the underlying layer.

\subsection{Influence of mixing}

By varying the rotation speed of the drum on which the substrate holder is fixed, one can change the amount of monolayers deposited per turn. This allows to estimate the efficiency of mixing between the subsequent $\mathrm{PbO}-\mathrm{TiO}_{2}-\mathrm{ZrO}_{2}$ layers. Figure 3 gives the estimated lead contents (same method as in 3.1), as a function of deposited monolayers per turn. The corresponding dielectric properties are given in figure 4 and the X-ray characteristics in table 2.

About 2 monolayers per turn may be deposited. Above this, intermixing fails. Previous work [9] has shown that the thin $30 \mathrm{~nm}$ seed PT layer practically doesn't interdiffuse with the overlying PZT: clearly, the intermixing depth must be much lower than this.

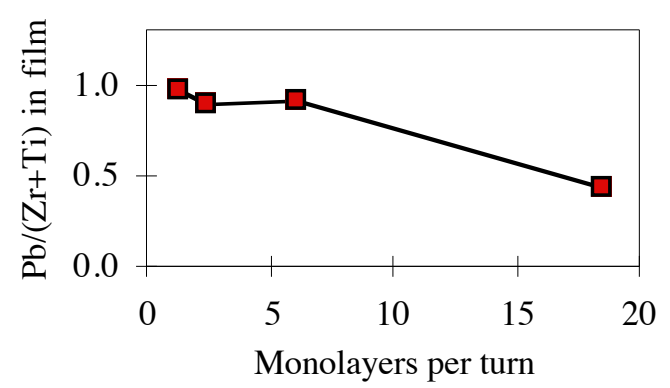

Figure 3. Evolution of lead content

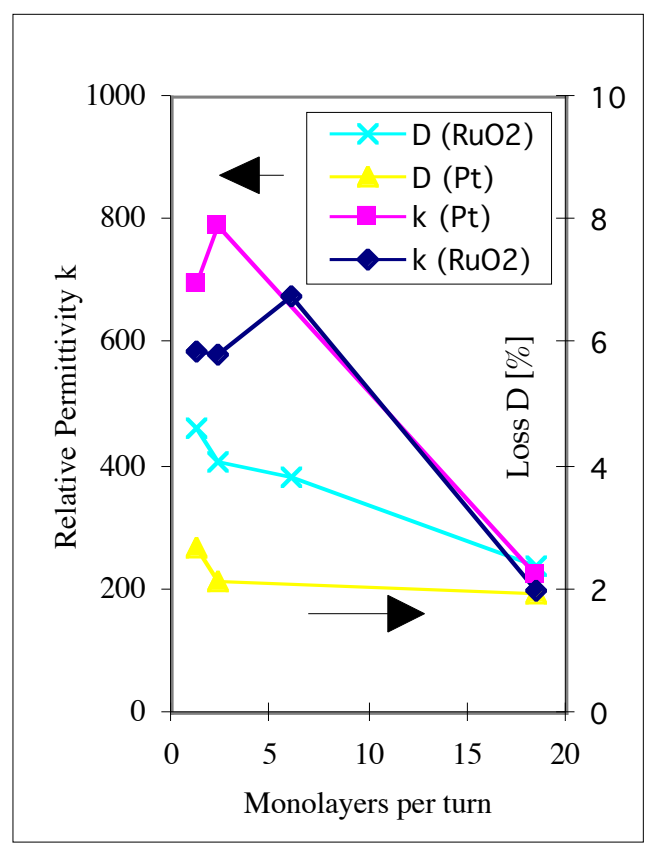

Figure 4. Evolution of dielectric properties

Table 2. X-ray analysis

\begin{tabular}{|l|l|l|}
\hline Monolayers per turn & on Pt & on $^{\mathbf{R u O}} \mathbf{O}_{\mathbf{2}}$ \\
\hline 1.3 & $<100 / 001>$ & random \\
\hline 2.4 & $<100 / 001>$ & random $* *$ \\
\hline 6.1 & random $* *$ & random $* *$ \\
\hline 18 & random $* * * *$ & random $* * * *$ \\
\hline
\end{tabular}




\section{3. $\mathrm{RuO}_{2}-\mathrm{PZT}$ interfaces}

A major problem encountered was very low adhesion of PT and PZT, indicating damage to the interface. We speculate that lead oxide bombardment could be a cause of the degradation (possible formation of intermediate $\mathrm{Pb}_{2} \mathrm{Ru}_{2} \mathrm{O}_{7}$ [10]). It was found to be necessary to add a $10 \mathrm{~nm} \mathrm{TiO}_{2}$ buffer layer. between the $\mathrm{RuO}_{2}$ and the PT. Such a small amount of $\mathrm{TiO}_{2}$ can easily dissolve during the deposition both into the $\mathrm{RuO}_{2}$ and into the PZT. Indeed, this method yielded clean and adherent $\mathrm{RuO}_{2}-\mathrm{PT}-\mathrm{PZT}$ interfaces, as evidenced from the high resolution TEM micrograph in figure 5. On Pt, no $\mathrm{TiO}_{2}$ was necessary, and direct deposition of PT-PZT gave clean interfaces [9].

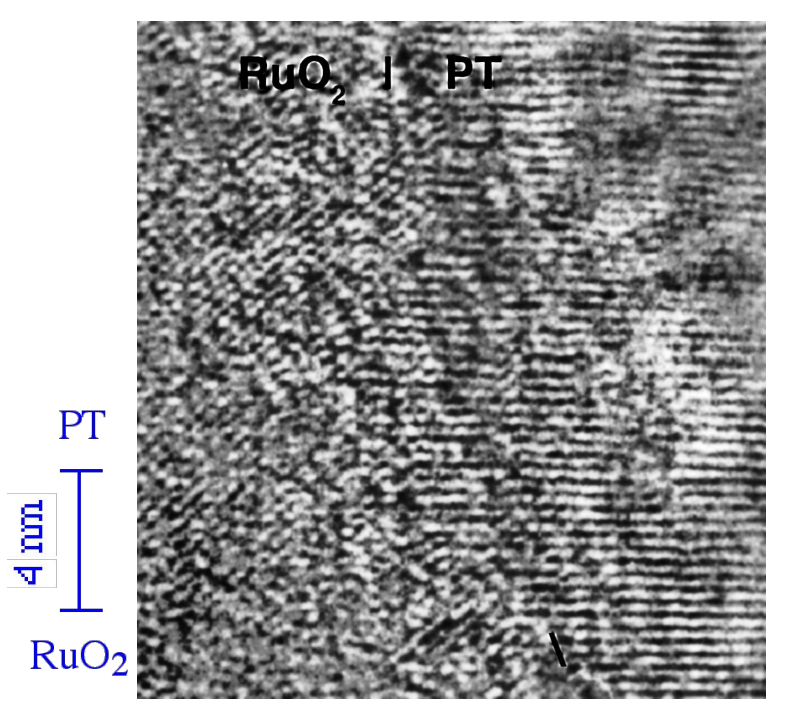

Figure 5. TEM of $\mathrm{RuO}_{2}$-PZT interface

\subsection{Film surface}

Field-emission SEM analyses of the sputtered films show a clean surface (figure 6), exempt from traces of second phase. This is expected for in-situ deposition, since lead loss is compensated during film growth.

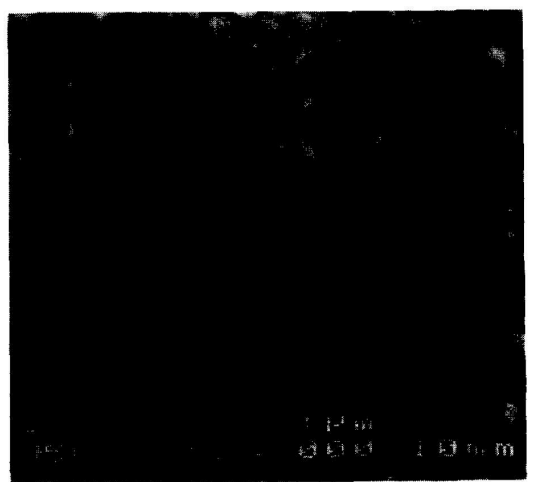

Figure 6. PZT Film surface on Pt 


\section{Conclusions}

An in-situ multimagnetron reactive sputtering process allowed the fabrication of PT and PZT films on Pt and $\mathrm{RuO}_{2}$ metallisations in the $550-600^{\circ} \mathrm{C}$ temperature range, yielding good surface microstructure and clean film-electrode interfaces.

When a suitable excess lead flux was supplied, PT grew with a strong preferred $<001>+<100>$ orientation on both metallisations. A $30 \mathrm{~nm}$ PT layer was enough to nucleate the same PZT orientation on Pt. On the random $\mathrm{RuO}_{2}$, however, the PZT grew randomly oriented, $30 \mathrm{~nm}$ of PT being insufficient to nucleate oriented growth.

Interlayer mixing during deposition was found to be limited to about 2 monolayers, above which the electric properties dropped markedly.

\section{Acknowledgements}

This work is financed by PPM, the Swiss Priority Programme in materials research. Also, the SEM photograph by J. Castano is gratefully acknowledged.

\section{References}

1. P.K. Larsen, R. Cuppens and G.A.C.M. Spierings, Ferroelectrics 128: 1-4, 1992. 128(1-4): p. 265-292.

2. G.-A. Racine, R. Luthier and N.F. de Rooj, in Micro Electro Mechanical Systems, 1993, Fort Launderdale, USA, IEEE.

3. K. Brooks, D. Damjanovic, A. Kholkin, I. Reaney, N. Setter, P. Luginbühl, G.-A. Racine, N.F. de Rooij and A. Saaman, Integrated Ferroelectrics 1995. 8 (1-2): p. 13-24.

4. O. Auciello, K.D. Gifford and A.I. Kingon, Appl. Phys. Lett., 1994. 64(21): p. 2873-2875.

5. G.A.C.M. Spierings, M.J.E. Uleneaers, G.L.M. Kampschöer, H.A.M. v. Hal and P.K. Larsen, J. Appl. Phys., 1991. 70(4): p. 2290-2298.

6. $\quad$ K.F. Dexter, K.L. Lewis and J.E. Chadney, Ferroelectrics, 1992. 134: p. 349-354.

7. G.J.M. Dormans, M. de Kejser, P.J. v. Veldhoven, D.M. Frigo, J.E. Holewijn, G.P.M. v. Mie and C.J. Smit, Chem. Mater., 1993. 5: p. 448-451.

8. R. Bruchhaus, H. Huber, D. Pitzer and W. Wersing, Ferroelectrics, 1992. 127: p. 137-142.

9. T. Maeder, P. Muralt, M. Kohli, A. Kholkin and N. Setter, British Ceramic Proceedings - Ceramic Films and Coatings, 1995. 53: p. 207-218.

10. C.K. Kwok, D.P. Vijay, S.B. Desu, N.R. Parikh and E.A. Hill, Integrated Ferroelectrics, 1993(3): p. $121-130$.

11. K. Sreenivas, I. Reaney, T. Maeder, N. Setter, C. Jagadish and R.G. Elliman, J. Appl. Phys., 1994. 75(1): p. 232239.

12. T. Maeder and P. Muralt, in Materials Research Society Symposium Proceedings, Vol. 341, 1994, San Francisco, USA, MRS, Pittsburgh, p. 361-366. 